\title{
Turkish EFL Instructors' Engagement in Professional Development
}

\author{
Ayfer Tanış a * (D), Kenan Dikilitaş ${ }^{b}$ \\ ${ }^{a}$ Kirklareli University, Kayalı Campus, Kırklareli, 39000, Turkey \\ ${ }^{b}$ Bahcesehir University, Beşiktaş Campus, İstanbul, 34353, Turkey
}

Received 1 November 2017 | Received in revised form 17 February 2018 | Accepted 18 February 2018

\begin{abstract}
While the beliefs and practices of teachers on professional development (PD) are generally considered to promote quality in education and raise teachers' awareness regarding teaching strategies, there is still limited research available into different PD models' effectiveness in providing teachers with practical knowledge. This research aims to explore the role of AR in Turkish EFL instructors' beliefs, and compare action research (AR), as a transformative model, with transmissive and transitional PD models. Qualitative data collected by means of semi-structured in-depth interviews were analysed by using constant comparative data analysis procedure. The participants were nine Turkish EFL instructors from a state university, selected according to purposive criterion-based sampling. The results revealed that the PD beliefs of Turkish EFL instructors conducting AR were different from those engaging in transmissive PD models in terms of access to and reflection on knowledge. The beliefs of the former group indicated strong evidence of a lifelong learning PD process, collaboration-based PD practices with intrinsic motivation, integration of inquiry based, experiential knowledge with reflective practice experiences, and a bottom up approach to PD. In contrast, the latter group showed short-term learning, and a theoretical knowledge transmission model depending on extrinsic motivation, presenting non-reflective, passive roles, with a top down approach. In this context, AR as an on-going PD activity is seen as highly effective for fostering teachers' practical knowledge.
\end{abstract}

(C) 2018 EJAL \& the Authors. Published by Eurasian Journal of Applied Linguistics (EJAL). This is an open-access article distributed under the terms and conditions of the Creative Commons Attribution license (CC BY-NC-ND) (http://creativecommons.org/licenses/by-nc-nd/4.0/).

Keywords: Action research; observation; reflection; professional development models

\section{Introduction}

There has been a growing interest regarding the professional development (PD) beliefs and practices of teachers to develop high quality standards in education. As there is a shift from conventional methods to more socio-constructivist and inquiry based models in teaching, the new developments emerged in the rationale of PD activities. As suggested also by Dikilitaş (2015), PD has changed a lot regarding its form and content owing to the recent developments in education, technology and pedagogy. In that sense, the concept of the teacher as a self-reflective, inquiring, and

\footnotetext{
* Ayfer Tanis. Tel.: +0905078419688

E-mail address: ayfertanis@gmail.com

http://dx.doi.org/...
} 
critically motivated practitioner increased interest in AR in ELT environments, as well as the notion of the teacher as a researcher (Burns, 2009). Williams and Burden (1997) emphasize that teachers create their own ideas and theories as each individual construct his or her own reality. Grounded on this, Bracey (2009) argues for the reevaluation of the teacher's role in both the classroom, and research. In this study, our central focus is on investigating how the beliefs of Turkish EFL instructors conducting $\mathrm{AR}$ as a transformative $\mathrm{PD}$ differ from the ones engaging in transmissive and transitional PD models. In this context, this qualitative study aims to explore the in-depth insights of EFL instructors by elaborating on their involvements and practices regarding PD.

\section{Literature Review}

Teacher PD is paramount to an effective educational system to enhance quality of teachers and considered as a key tool to help teachers update their knowledge, skills and practices. In that sense, it has recently witnessed rapid changes in parallel with the shifts and developments in educational paradigms, pedagogies, technology, and new trends that have considerably changed the understanding of the field regarding how teachers learn to teach. In the last few decades, a number of research conducted on second language teacher education, specifically on teacher cognition (Borg, 2003; Freeman, 2002) has changed the previous positivist conceptualization of teacher learning with a shift from the traditional, linear and hierarchical view of teacher learning and development to a more holistic, collaborative and socio-constructivist approach (Korkmazgil, 2015). In this context, especially, the structure and content of PD models have moved away from conventional approaches or the traditional delivery approaches and transmissive practices requiring teachers to attend one-shot "sit-andget" in-service training and workshops to a more inquiry-based, socio-constructivist view of teacher development with transformative purpose regarding the language teachers as co-constructors of knowledge who can make more autonomous decisions about their own teaching practices with a specific group of learners in particular settings (Korkmazgil, 2015, p.21). In this regard, as indicated in the categorization and organization of PD models of Kennedy (2005), there is an accelerating capacity for teacher autonomy as teachers move from transmission, through transitional to transformative categories. Grounded on these, as Johnson (2006) claims, top-down professional development models have given place to alternative professional development models that lead to self-directed, collaborative, inquiry-based learning which is directly relevant to teachers' classroom lives.

Conventional approaches include training model that indicates the purpose of transmission including one-shot in-service programmes, workshops, and seminars conducted by outside experts who transfer co-constructed knowledge by other experts again (Cullen, 1997). These are widely criticized to be course-focused, input-based, externally-defined, deficit-oriented, one-way knowledge transmission, and have shortterm objectives and lack of impact on practice (Atay 2006, 2008; Borg, 2015; Burns, 2005; Feiman-Nemser, 2001; Guskey, 2000; Kennedy, 1998; Lieberman and Wilkins, 
2006; Little, 1993, 1999; Özer, 2004; Richards, 2008; Uysal, 2012). In this top down approach, by means of in-service trainings, seminars and workshops, change is considered as the knowledge transmission from educators or policy makers to teachers" (Darling-Hammond, 1990). Therefore, teacher training is significant for presenting the trainees necessary terminologies and methodological concepts that can be considered as common currency of language teachers (Mann, 2010). Ingvarson (1998) argues that even if these traditional approaches with the aim of transmission are required for PD, they are not sufficient in themselves. In the same vein, VillegasReimers (2003) proposes that with the new notion of teachers as professionals, and their preparation for a lifelong learning process, the conception of teacher training is no longer fitting as teachers are accepted as active participants in their own growth and responsible for their own development within this new perspective.

Similarly, Borg (2015) suggests that "these externally-driven PD practices might result in teacher as consumer modes of teacher learning" (p. 5). Instead of taking the responsibility of one's own learning through gaining autonomy, teachers might feel that their day-to-day practice is less important than external inputs in the training room. Such a conceptualization to PD is considered to restrict these teachers' constructive contributions and voluntary participation in the trainings (Borg, 2015). Another overall criticism of these kinds of trainings is that they cannot succeed in fostering long-term beneficial impacts, promote the targeted developments in teachers' perceptions and improve their teaching practices (Choi and Andon, 2014; Kubanyiova, 2012).

However, with the most recent view of $\mathrm{PD}$, the teacher is more likely to be viewed as a "knowledge generator" (Borg, 2015, p.6). In this respect, Borg (2015) claims that high quality PD practices based on constructivist view of development embrace the needs of teachers and students, teacher involvement in decisions related to content and process, teacher collaboration, exploration and reflection with attention to not only practices but also beliefs.

From a socially situated perspective, with the purpose of transitional PD (Kennedy, 2005), it is the teacher who sets their own specific goals, determines the activities and resources to be used and manages the time for $\mathrm{PD}$, rather than depending on presentation and management by others (Turhan and Arıkan, 2009). In transitional PD models, including the constructivist approach, such as peer coaching, mentoring, and self-directed PD, development is conducted bottom up, with the active participation of teachers for professional sharing and critical reflection that lead them knowledge adaptation in authentic contexts (Darling-Hammond, 2006). As Johnson and Golombek (2002) stated, PD is a process of reshaping teachers' existing knowledge, beliefs and practices, rather than simply imposing new theories, methods, or materials on teachers. In this socio-constructivist view, teachers both possess knowledge and can create that knowledge (Johnson and Golombek, 2002).

Having reviewed the relevant literature, in this bottom-up approach, as Fullan and Miles (1992) suggest, the aim is to gain specific, concrete and practical ideas that are 
directly applicable to daily classroom practices, as well as taking a pragmatic approach to PD. Therefore, teachers need much more practical tools, such as action research (AR), to help them resolve problems or issues by being actively involved with them in their own classrooms (Burns, 2010; Freeman, 1998; Mills, 2007; Richards and Farrel, 2005). As Kennedy (2005) states an action research model clearly has significant capacity for "transformative practice and professional autonomy" (p. 246). In this regard, Burns (2005) believes that AR enables teachers to act as researchers and develop personal goals, values and beliefs about practice providing an opportunity to gather information about not only how they teach but also how well their students learn. As Mills (2007) points out, AR facilitates teachers to gain insight, develop reflective practice and create positive changes not only in their professional learning but also in their classrooms. According to Burns (2010), in the process of AR, a teacher becomes "an explorer of his or her personal teaching context", while at the same time being one of the participants in it (p. 2). Therefore, AR is a type of inquiry that aims at discovering, developing, or monitoring changes in classroom practice through interrogating one's own and others' practices and assumptions. Also, as Dikilitaş (2015) points out, this inquiry-based PD encourages trainees to research their own practices, understand more about their own classroom context and come to a stage where they make informed decisions for development or change in the existing practices. This puts an emphasis on reflecting critically and conceptualizing alternative perspectives on a problem, which lies at the heart of PD (Schön, 1983).

In this context, the beliefs and practices of teachers on PD should also be taken into consideration to promote quality in education and raise teachers' awareness regarding their PD. To our best knowledge, the literature on the factors associated with teachers doing research has not so far provided in-depth information for the comparative analysis of teachers' beliefs in terms of transmissive versus transformative or inquirybased PD practices. Therefore, further research is needed to contribute to the studies to have much deeper and more detailed understanding on the role of AR as a PD tool by elaborating on the PD perceptions of Turkish EFL instructors. This study therefore aims to investigate the role of AR in Turkish EFL instructors' beliefs and compare it with that of instructors engaged in transmissive and transitional PD models. To this end, the research question guided the study as follows:

How do the beliefs of Turkish EFL instructors conducting AR as a transformative PD differ from the ones engaging in transmissive and transitional PD models?

\section{Method}

\subsection{Research Context and Participants}

As noted, participants were nine Turkish EFL instructors working in Foreign Languages Department in a public Turkish university. The university, founded in 2007 , is situated in a city on the northwest of Turkey. The university offers various 
bachelor, master's and doctoral degree courses using either Turkish or English as the medium of instruction.

We collected the data from 9 of our colleagues currently working in the Foreign Languages Department as EFL instructors. The colleagues voluntarily and enthusiastically participated in the study. Two had six years of teaching experience and 7 had at least eight years of experience in teaching Basic English and Vocational English courses in elementary, pre-intermediate, intermediate and upper intermediate levels. While five reported their highest relevant qualification was a Bachelor's degree, with teaching diplomas and postgraduate academic degrees; four had MA degrees but were then attending a $\mathrm{PhD}$ program in ELT. The participants reported different job experiences and as a background, reflected working in multiple institutions; one-third taught in private language schools and universities, while the others worked in government schools before their current job. The participants were selected by means of purposive criterion according to their recent professional development experiences, in accordance with our major purpose: how engagement in transmissive, transitional, and transformative PD could influence the instructors' beliefs.

\subsection{Research Methodology}

In order to gain an in-depth understanding and elaborating on how the beliefs of Turkish EFL instructors conducting AR as a transformative PD differ from the ones engaging in transmissive and transitional PD models, a qualitative collective case study approach is adopted in this study. As described by Stake (2000), collective case study consists of more than one case to investigate a phenomenon, population, or general condition (p. 437). In this vein, the participants representing different cases working in the same single context were selected purposively, depending on criterionbased sampling, to enable a clear comparison across the three categories.

\section{Collective Case Study model}

Adapted from Kennedy (2005), the following PD models characterized the nature of $\mathrm{PD}$ engagement of the 9 instructors in this study.

\section{Case 1}

a. 3 instructors engaging in transmissive PD (Tm PD)

\section{Case 2}

a. 3 instructors engaging in transitional PD (Ts PD)

\section{Case 3}

a. 3 instructors engaging in transformative PD (Tf PD)

According to the criterion of their PD perceptions and practices, three EFL teachers were selected for each category: those dealing with Tm PD models including conferences, workshops, seminars and in-service trainings; those depending on Ts 
PD models including peer coaching, peer observation, discussion boards; those conducting $\mathrm{AR}$ and relying on Tf $\mathrm{PD}$ practices. In this regard, as a researcher working in the same institution, the first author has background information regarding the participants' perceptions, practices and PD involvements. However, for the trustworthiness and credibility of the data, the first author had pre-interviews with the participants to determine and make sure whether they fit into the criteria of a certain category of PD.

The pure qualitative data for this study were collected by means of semi-structured interviews to investigate the beliefs generated by training-based versus inquiry-based PD practices. In brief, semi-structured interview questions allowed the collection of in-depth data regarding the comparison of Tm and Ts based PD models, with AR as a Tf PD model. In parallel with this, follow up interviews were also conducted to gain detailed understanding and in-depth insights on the role of $\mathrm{AR}$ as a PD tool, by elaborating on the PD perceptions of Turkish EFL instructors. For the credibility of the data, the recurrent interviews were arranged for longitudinal data collection. Both semi-structured interviews and follow up interviews were in English, the second language of the participants, and examples of their statements are reproduced. As aforementioned, as the participants were colleagues of the first researcher at a state university located in northwest Turkey, as an interviewer and a researcher, the first author was well known to the participants and had no difficulty in arranging meetings with them.

Before each interview, the first author briefly discussed its purpose, the scope of the study, and use of the audio-recorder. All participants provided consent for the recording and transcription of interviews. Each recurrent interview took approximately an hour and was conducted in a quiet room at the university at prearranged times in the evenings. Each interview was audio-recorded, and the first researcher took notes during the interview to create a context for the interviews via taking the opinions of the participants before and shortly after the interview process (Kvale, 1996). To strengthen the findings, the first researcher asked detailed questions regarding how the perceptions, practices and PD characteristics that facilitate developing practical knowledge are reflected, by elaborating on the PD models the participants are involved in. At the end, after signaling the end of the interview, the first author allowed each interviewee to ask questions or to raise issues.

This qualitative research shows the key characteristics of grounded theory that can incorporate a systematic approach, a flexible emerging design, and the use of active codes to capture the experiences of participants (Creswell, 2012) and accordingly depend on the constant comparative data analysis in design. In this regard, we followed a procedure involving the simultaneous and sequential collection and analysis of data which means that the sampling is intentional and focused on the generation of a theory (Creswell, 2012). In accordance with grounded theory research, we initially engaged in data gathering process by means of semi-structured interviews, and then sorted it into categories, collected additional information 
regarding follow-up interviews, and compared the new information with emerging categories. Therefore, the process of developing categories of data and information gradually formed the constant comparative procedure. Constant comparison is an "inductive (from specific to broad) data analysis procedure" of generating and connecting categories by comparing incidents in the data to other incidents, incidents to categories, and categories to other categories with the aim of grounding the categories in the data (Creswell, 2012, p.434). In the light of the information, this study focuses on inductive analysis process, as we do not have pre-determined categories or pre-set themes, rather we expected the data to create new themes and construct new theories at the end of the data analysis process. In this vein, as Glaser (1978, cited in Charmaz, 2000, p. 515) pointed out after transcription process, raw data coming from the interviews were formed into indicators, which were grouped into several codes and then placed into more abstract categories. In this process, we were constantly comparing indicators to indicators, codes to codes, and categories to categories with the aim of eliminating redundancy and developing evidence for categories (Creswell, 2012). In addition, we compared the emerging scheme with the raw data to ground the categories in the information collected during the study.

For data analysis, we also made use of cross-case analysis (Miles and Huberman, 1994) to study each, individual case as a whole entity, and coded the interview responses of each instructor line-by-line, then we followed a comparative analysis of occurring themes as already mentioned. After we transcribed each interview and coded all the data line-by-line, approximately 80 codes emerged initially. Accordingly, in order to regulate and discuss the codes to identify emergent themes, a table representing the study's findings was developed and each case was analysed in depth by examining the beliefs of instructors engaging with the conventional training based models and observation based PD models and comparing these with beliefs generated by AR. As categories emerged, by means of a constant comparative method (Charmaz, 2000) codes and then categories were compared, refined, expanded, or deleted whenever needed. The number of codes that were decreased around 40, then divided into ten complementary sub-categories including dichotomies. To determine all of the categories, this process was continued until agreement was reached on all categories. Finally, under two major categories, six subthemes emerged. This cross-checking process of coding in terms of the major categories catered for "thoroughness for interrogating the data" and allowed for discussion that enhanced insights of the coding (Barbour, 2001, p. 1116).

According to the final categories, we interpreted the findings in light of the overall focus of the study on comparing the beliefs and practices of ELF instructors regarding the PD models. Finally, the results organized in relation to the comparative analysis were presented in a descriptive narrative style, followed by supporting representative statements from the interviews.

In terms of credibility and trustworthiness, the first author has written regular self-reflections in research involvement process and has been supported by the second author, qualitative research expert in each step of the study, especially for inter-rater 
reliability while checking the codes and analysing the results. Also, methods of member checking (Janesick, 2000) and respondent validation (Creswell, 2012) were used in order to confirm findings regarding the data analysis process. We shared the findings with interviewees either face to face or via e-mail to foster respondent validation and participant feedback, and then conducted member checks with an experienced qualitative expert for confirmation. In addition, pattern matching was accomplished as the emerging patterns and themes found in the data were matched with the predicted patterns regarding the theoretical aspects, as evident in the quotations of the participants.

\section{Results}

Interviews centered on the comparative analysis of teachers' beliefs in terms of training-based versus inquiry-based PD practices, to gain an in-depth understanding on the role of AR as a PD tool. Two primary categories were identified as (a) access to knowledge, and (b) reflection on knowledge. Additionally, within each of these primary categories, subcategories were developed that provide further information regarding the comparison of $\mathrm{AR}$ as a TF PD with Tm PD models consisting of seminars, conferences, workshops and in-service trainings and Ts PD models such as observations, peer-coaching, field discussions. The subcategories under the first primary category "access to knowledge" include "lifelong learning vs. short-term learning", "collaboration vs. transmission", "intrinsic motivation vs. extrinsic motivation", "experiential knowledge vs. theoretical knowledge"; while the second primary category "reflection on knowledge" consists of the subcategories of "reflective practice vs. non-reflective" and "bottom up approach vs. top down approach". In this vein, the results indicated that the beliefs and practices regarding PD instructors conducting AR differ from those engaging in Tm and Ts models.

\subsection{Access to Knowledge}

\subsubsection{Lifelong Learning vs. Short-term Learning}

When asked to define PD and clarify what they understand from it (section one, question 1 and 2), the responses of instructors engaging in AR were significantly different from those engaging in training based PD models. While the former conceptualizes PD as a life-long learning process, the latter defined it as short term, one shot training programs. An analysis of the spontaneous metaphors used to explain the clarification of PD suggests the differences in the two conceptualizations. For example, AR instructors cited terms such as "journey', "exploration", "road", "growth", "survive", metaphors associated with life-long learning and linear progress, stating that:

I think PD is a kind of continuous and endless process of gaining knowledge and training ... (Tf 1$)$

PD is beyond limits. You cannot restrict to only some basic activities. It is a lifelong learning process .... (Tf 2 ) 
PD is a long journey. ... More than that, PD is necessary for us to survive in our teaching context (Tf 3)

In this regard, the Tf responses showed similarities in terms of their accepting PD as "a life-long learning", "dynamic", "on-going" and "endless process".

I would define PD as lifelong because it refers to a dynamic and constant process of learning. (Ts 1)

PD activities aim to develop long-term goals and enhance understanding of different styles of teaching. I can define it as life-long learning (Ts 3)

On the other, the responses of Tm instructors indicated short-term beliefs and conceptualizations of PD, emphasizing "limited period of time", "updating knowledge", "current trends", "modern and recent approaches" and metaphors they used as "quick mindfulness", "one-shot", "sit and get", "quick way Also, the Tm responses sometimes criticised the PD activities as "out of context and inapplicable". One instructor even used the metaphor "alien". Examples from the data include:

I try to update myself to technology and new approaches of education (Tm 1)

Professional development, in practice, is one-shot session of training opportunity, in our case for teachers that try to create some sort of quick mindfulness regarding the educational practices of teachers within a limited period of time. (Tm 2)

... Sometimes, I view the presenters in the seminars like aliens as they do talk about something imaginative and perfectly arranged classrooms, such as technologically well equipped. (Tm 3)

\subsubsection{Collaboration vs. Transmission}

To gain insights into EFL instructors' beliefs and practices regarding PD (section 2, question 1 and 2), they were asked questions about their activities. While the responses of ARs indicated strong evidence on collaborative focus, including the coconstruction of knowledge by means of idea and information sharing the Tm responses showed the knowledge transmission aspects, receiving ideas and information rather than sharing or co-construction with students and colleagues.

The Tf responses put an emphasis on collaboration based PD, evidenced by words such as "cooperation", "sharing", "collaboration", "working together", "feeling of community", "not working in isolation", "keeping in touch with colleagues", and "constructivist points of view". Similarly, their responses indicated that they coconstruct knowledge, as it is evident their stating "reshaping knowledge", "build ideas", "putting the theory into practice", "create new ideas". Tf PD participants said the followings:

Sharing experiences and cooperation give me a feeling of community. As teachers, we are not working in isolation but working together and we face similar challenges. (Tf1)

Professional sharing with my colleagues helps me to construct new ideas, create new solutions regarding my students' needs and interests. (Tf 2) 
I built a broader perspective upon teaching strategies and practices, adapt knowledge to my context regarding my students' needs and interests. (Tf 3)

In the same vein, the Ts PD participants also focused on the importance of "sharing experiences" and "cooperation" by means of peer coaching and peer observation PD practices as shown in their statements:

.... meeting with other people in my field, sharing and exchanging ideas with my colleagues contributes to our teaching practices. (Ts 1)

I observed my students and realized that they learned many things from each other. Everything begins with collaboration because knowledge grows by sharing. (Ts 2) 
In contrast, an analysis of the Tm responses reveals phrases such as "giving ear to experts", "depending on the experienced teachers", highlighting the acceptance of PD activities and practices as a knowledge transmission rather than collaboration or coconstruction of ideas. Furthermore, some Tm participants were seen to criticise Tm PD activities as being "utopic", inapplicable", and resulting from a "lack of hands-on experience", in line with "knowledge transmission level", as indicated in the following quotations:

You give ear to experts and experienced teachers within the field when you attend workshops and conferences. (Tm 1)

More "hands-on experiences" of teaching might be an important key for bridging the gap between what teachers know and what they are expected to perform in their classes. (Tm 3)

It is utopic for me to apply some of the activities in the seminars and workshops in a classroom with 70 engineering department students. (Tm 2)

While the responses of Ts participants indicated collaboration based PD, their comments revealed that their PD practices stayed in knowledge transmission level:

I learnt about technology-integrated instruction and new tech tools in the seminars and conferences I attend. (Ts 1)

The workshop offered very useful advice on action research. (Ts 2)

This one shot in-service training provided me knowledge on how to use storytelling to increase students' proficiency levels in EFL setting. (Ts 3)

\subsubsection{Intrinsic Motivation vs. Extrinsic Motivation}

An analysis of responses to the questions regarding whether or not the PD participation is on volunteer basis show the facilitative and hindering factors, (section 2 , question $1,2,3,4)$. This reveals that the Tf beliefs point to intrinsic motivation, and the Tm responses, extrinsic motivation.

While expressing their PD beliefs and practices, Tf teachers used the words and phrases such as "taking responsibility of own growth", "volunteer basis, "willingness", "feel the need", "feel oneself obligatory", "feeling deep inside". These indicated intrinsic motivation as a facilitative factor, illustrated by the following statements:

$\mathrm{PD}$ is something inside me. You come across with new issues, concepts, problems in your teaching environment and you want to advance your knowledge in those areas you started to interest, and you want to do more, I mean you want to act on! Then, you always want one step more and more. It goes on and on. (Tf 1 )

I feel the need to improve my pedagogical knowledge to be able to help my students on their journey to learn English. (Tf 1)

As I am taking responsibility for my own growth as a teacher and a researcher, participation in $\mathrm{PD}$ activities are on volunteer basis for me. (Tf 2) 
I believe in the value of PD and I feel obligatory to be an active teacher, scholar, and learner throughout my career stages. Thus, I try to plan and organize professional learning for me as I regard PD activities indispensable part of my life. (Tf 3)

Tm and Ts responses were mixed. They showed the impacts of extrinsic motivation, in negative terms such as "workload", "financial restrictions", "time management problems", but also positive statements: including "support of institution and family", "financial support".

Without the support of my institution or my family, I cannot participate in conferences and seminars. (Tm 1)

I have to lecture in different faculties with various levels of students, it is really hard for me to spend broad time for my P.D. process. (Tm 2)

I think both facilitating and hindering factors affecting PD stem from extrinsic factors such as workload, financial and institutional issues. (Tm 3)

When school offer free time, sponsor partially and encourage us to attend, I do generally easily participate in useful workshops, seminars, in-service trainings. $(\mathrm{Ts} 1)$

My participation to seminars and conferences generally depend on my institution, as we have to take permission from the school for national and international conferences. (Ts 3)

\subsubsection{Experiential Knowledge vs. Theoretical Knowledge}

The responses of Tf, Tm, and Ts participants show that while the Tf participants consider themselves as knowledge generators through gaining experiential knowledge and engaging in the exploratory practices of $\mathrm{PD}$, the Tm and Ts participants regarded themselves as knowledge receivers, in other words, consumers of received or theoretical knowledge.

While all Tf respondents indicated the necessity of teacher-driven experiential knowledge and significance of exploratory practice, they also emphasized that this should be achieved through for autonomous, inquiry-based PD. Using terms such as "fresh inspiration", "explorer", "practical knowledge", "digging deep" and "hands-onexperiences" and the metaphor "staying afloat in an ocean" are the indicators of this theme.

Initially, the instructors engaging in $\mathrm{Tf}$ as a PD tool emphasized the necessity of inquiry-based $\mathrm{PD}$ leading to autonomous hands-on experiences and insider perspectives, rather than externally-driven $\mathrm{PD}$ practices. This is evident in the following examples from the data:

You investigate, explore the problem, learn more about via reading, act on it and get the results in real PD. (Tf 1) 
AR allows me to explore my own world with my own students in my own teaching context. AR is a way for me to answer questions that puzzle me and a way to generate or enhance practical knowledge. (Tf 2)

It is crucial and necessary to have hands on experiences while conducting research as with insider perspective, the real problems that the real students have will be reflected. (Tf 3$)$

I am an insider in the class and aware of what is going on in terms of students' needs, concerns, strong and weak features. My students give me fresh inspiration. (Tf 3)

These Tf themes reflected beliefs, practices and practical knowledge and emphasize gaining experiential knowledge and integrating exploratory practice, i.e. becoming knowledge generators, as evident in the following statements:

AR makes me explore more about the essence of my profession ... When I dig deep, I see the larger picture and continue exploring more and more. Therefore, it makes me "stay afloat in an ocean". (Tf 2)

... action research helps you find the best practice to get rid of a specific problem as you are an investigator, "explorer" of the problem, learner about via reading, actor and problem solver to get the results ( $\operatorname{Tf} 1)$

PD especially action research helped me explore different learner styles in my classroom and prepare appropriate materials. (Tf 3)

In contrast, Tm and Ts approaches were shown to depend on externally or expert driven, and theoretical knowledge with outsider perspectives. Therefore, these put teachers in the role of consumers of knowledge, as revealed in the following statements:

Experts or more experienced teachers, and more knowledgeable ones in the field, who present at conferences, seminars, webinars, give you many ideas that you simply transfer to the classroom. (Tm 1)

I am apt to participate in the seminars especially about ELT and educational technology by experts who are indeed more experienced than me, shown even in their speech. (Ts 2)

Tm and Ts participants depend on expert driven, theoretical based PD models, which are criticised as "utopic", "unpractical" and "inapplicable" as evident in the following:

Unfortunately, PD activities aren't effective for developing practical knowledge as there is such a big gap between theory and practice in my profession that neither academicians nor practitioners are able to bridge. (Tm 2)

Seminars and workshops do not consider my needs and interests; they do not make any sense for me as they do not include practical information. It is same when I observe my colleagues, as I hardly find ideas appropriate for my own context. (Ts 3) 


\subsection{Reflection on Knowledge}

\subsubsection{Reflective practice vs. Non-reflective}

There was a clear difference between $\mathrm{Tf}$ and $\mathrm{Tm}$ instructors regarding implementation of learning from PD activities, and their perceptions of themselves as being reflective in PD process and in practices (third section, questions 1, 2, and 3). Unlike Tm participants, Tf participants indicated reflective practices.

I consider myself as a reflective teacher. I believe that the PD activities that I attend are reflected in my teaching as I internalize them naturally. (Tf 1)

I believe that I am a reflective and more attentive and responsive to student learning, as I am doing my best to engage in critical and reflective review of their own teaching, for example self-monitoring myself and conducting an AR. (Tf 2)

TR and AR that I carry out give me great feedback and reflection upon the activities that I try to apply in the classroom. (Tf 3)

However, these attitudes are not typical of all teachers. Two specific reasons for being non-reflective are mentioned for by Tm participants:

It is hard to reflect PD activities in practice and teaching. It is sometimes because of the time management problems and students' interests and academic levels. Another thing is related to the setting. (Tm 2)

I don't find myself reflective actually. As I don't have a chance to apply what I have learnt from PD activities to my teaching context because, in general, they aren't parallel with my students' needs. (Tm 3)

\subsubsection{Bottom up vs. Top down approach}

The responses of instructors revealed that that each tended to be associated more with either top-down or bottom-up processes. Tf responses indicated a bottom up process with positive beliefs and experiences, while the Tm responses portrayed a topdown process with a mixture of positive and negative experiences. An examination of linguistic markers that relate to agency shows, for instance, that passive forms tend to be used to describe a more top-down process. Agency is also shown in the choice of lexis, specifically, nouns, verbs, and adjectives.

However, some of the beneficial experiences were related to top-down PD, indicated in the reporting verbs and sentence structure used. Also, the lexis the participants used illustrates an appreciation for top-down craft learning or for received knowledge. This is evident in the following:

I think PD is a process, necessarily updating the teacher's proficiency with new techniques and rapidly changing technology. Thus, I like reading dissertations and publications in my field as they indicate the most recent topics in ELT. (Tm 1)

The topics that were covered in the workshop were contemporary vocabulary teaching strategies that aim to enhance our practical knowledge although the implementation is the toughest part. (Tm 2) 
PD is helping or training teachers to be more effective and develop their teaching methodology and PD is the only way to bring yourself up to date with the current methods, recent tools and modern approaches. (Tm 3)

In contrast to the beneficial experiences and reflections reported on top-down process, there are also disappointing experiences. The responses of the instructors specifically in second and third section of the interviews indicated the complaints that focused on three main areas: First, content related, including sessions that were offtopic, repetitive, or impractical; second, management issues, consisting of unsubstantiated observations about teaching without providing for participant feedback; and finally, organizational problems involving presentations in crowded rooms to uninterested participants. These are evident in the following quotations:

The things that the speakers in the conferences mention generally do not correspond to needs and interests of my students and my teaching context. I cannot apply them in my context with crowded classrooms and low-level students. (Tm 2)

I am trying to gain insights how to improve my teaching strategies and enhance academic knowledge of teaching on an individual basis, with the help of the seminars I participate in as the speakers and the experts give various sample cases and incidents in their speech. However, it is sometimes utopic to apply them in my own setting as they don't reflect the reality. (Tm 3)

However, there was very little negative comment in the responses of $\mathrm{Tf}$ and $\mathrm{Ts}$ participants. The beneficial experiences reported for bottom-up PD, relates to active engagement and have critical engagement and participation, shown in the following Tf comments:

$\mathrm{AR}$ allows me to move one-step further in my growth as a teacher, learner and a researcher. (Tf1)

I strongly believe that AR takes place in the classroom; I mean the site where we as teachers spend most of our professional lives, rather than in the "training room". (Tf 2)

Taking part in an international conference and presenting my AR was an awesome experience for me as I had a chance to express my practical views on the role of culture-integrated instruction on students' learning. (Tf 3)

Similarly, Ts participants' responses revealed positive experiences regarding bottom up approach in PD, as evident in the following claims:

Via peer observations, I have a chance to monitor my colleagues regarding their teaching practices, strengths and weaknesses and this gives me a chance to critical engagement in received knowledge. However, when I conduct an action research, I involve in the process with my students and it is much more effective for me compared to the other PD activities. (Ts1)

By means of peer-observation, you watch your colleagues in action and can easily evaluate one's teaching; you share your ideas with them and vice versa. Thus, it 
really helps to gain a deeper and more objective understanding for determining your colleagues and your own weaknesses and strengths in your teaching practice. (Ts 2)

While interacting and discussing with my colleagues, I feel myself more motivated and strong as we share our experiences and broaden our perspective. (Ts 3)

To conclude, the comparative analysis indicated significant differences in Tf PD beliefs in terms of access to and reflection on knowledge. Tf beliefs showed strong evidences of lifelong learning, collaboration-based practices with intrinsic motivation, the integration of inquiry based, experiential knowledge with reflective practice experiences, and bottom up approach. In contrast, the Tm beliefs indicated short-term learning, theoretical knowledge transmission model depending on largely extrinsic motivation, presenting non-reflective, passive roles with top down approach. On the other hand, the interviews, showed that Tm's participants' PD beliefs were similar to those of Tf participants, and include long-term objectives, and the need for collaboration-based practices, despite their exposure to knowledge transmission models with expert-driven PD activities and their generally extrinsic motivation.

\section{Discussion}

The variation in these three PD models in relation to the reviewed literature is discussed in this section, to gain in-depth insights for the PD models that facilitate practical knowledge for teachers.

The findings of the study regarding the PD beliefs of EFL instructors conducting $\mathrm{AR}$ as a Tf model supported the reviewed literature, for example, teachers who were engaging in research considered themselves as knowledge generators (Borg, 2015) independent of expert knowledge or externals, contrary to conventional training based PD models. As Wyatt and Dikilitaş (2015) highlight, encouraging teachers become more efficacious through CPD engages them as knowledge generators and research engagement facilitates them develop experience and gain deeper practical knowledge. In this regard, the responses of participants conducting AR for their PD indicated that by means of AR that facilitates developing practical knowledge in their own teaching context, they can only fully resolve the problems faced when actively involved as an insider (Burns, 2010; Freeman, 1998; Mills, 2007; Richards and Farrell, 2005).

On the other hand, the beliefs of EFL instructors depending on Tm PD models indicated short-term learning and knowledge transmission characteristics, showing the dependence on outside experts. Such findings seem to confirm criticisms of Tm PD models as externally-defined, deficit-oriented, one-way knowledge transmission, with short-term objectives and lack of impact on practice (Atay 2006, 2008; Borg, 2015; Burns, 2005; Feiman-Nemser, 2001; Guskey, 2000; Kennedy, 1998; Lieberman and Wilkins, 2006; Little, 1993, 1999; Özer, 2004; Richards, 2008; Uysal, 2012).

Furthermore, the findings revealed that the EFL instructors that participated at conferences, seminars and training programs for PD cannot reflect on or implement 
learning in their own classroom settings because of the lack of relevance of seminar content, including sessions that do not address to the needs of the teachers and students, and experts without adequate background knowledge regarding the actual classroom environment and problems. Therefore, these Tm PD models remain at the knowledge transmission level, rather than developing practical and applicable knowledge. On the contrary, as the findings of the study supported the research the teachers carry out with their learners and colleagues gives them an opportunity to construct new knowledge through "mutual development" (Dikilitaş, 2015, p.48). In this regard, by means of $\mathrm{AR}$ as a Tf PD model, a teacher becomes "an explorer of his or her personal teaching context", while at the same time being one of the participants in it (Burns, 2010, p.2).

Another finding that is, in accordance with the literature, the beliefs of $\mathrm{Tm}$ are associated with top down process, but the beliefs of Tf have strong implications for bottom-up process. As Wyatt and Ager (2016) stated, opportunities for PD are necessary to support teaching as lifelong learning and incorporate a nurturing bottom-up approach that leads to teacher empowerment. However, top-down approaches, including formal courses and workshops on predetermined topics may not relate to teachers' needs and interests. Therefore, the findings of this study support the view that excessive top-down CPD can be "demotivating", even in a context where some teachers may conceptualize PD as essentially a top-down process (Wyatt and Ager, 2016, p.1). Similarly, even respondents that viewed PD as a top-down process in this study admitted that they sometimes lose their intrinsic motivation because of the ill-defined and repetitive training topics, management problems, experts addressing issues irrelevant to students' needs and interests, and the lack of provision for feedback. However, in contrast to such disappointing experiences, the participants conducting AR mentioned only beneficial and positive effects regarding the bottom up process of $\mathrm{PD}$, including autonomous practices, exploratory and practical knowledge, reflective practice, and supported, bottom-up PD that can be "liberating" (Wyatt and Dikilitaş, 2015, p.19). In this regard, by means of engaging in AR, the participants strongly believe that they not only improve practices, but also develop and strengthen their professionalism, which results in higher quality learning and teaching.

In this context, the beliefs of EFL instructors conducting AR as a Tf PD model are very different from those engaged in the Tm and Ts PD models. Specifically, AR should be considered to be a vital PD tool, effective in terms of gaining practical knowledge, developing reflective practice, providing autonomous teaching and learning process with long term objectives.

\section{Conclusions}

To conclude, this study sheds light on how the beliefs of Turkish EFL instructors conducting $\mathrm{AR}$ as a Tf PD practice differ from those participating in the other two models. Specifically, the beliefs of the instructors show significant differences in terms of access to and reflection on knowledge. In this regard, the study illustrated that 
beliefs of Tf PD group emphasized the necessity of lifelong learning, collaborationbased practices based on intrinsic motivation, integration of inquiry-based, experiential knowledge with reflective practice experiences, in accordance with a bottom up approach. In contrast, the beliefs of Tm indicated short-term learning, theoretical knowledge transmission model depending on extrinsic motivation, presenting non-reflective, passive roles associated with top down approach. As for the beliefs of instructors participating in Ts PD practices, these are similar to those based on Tm PD models, as the approach also depend on knowledge transmission models with expert-driven PD activities, and have extrinsic motivation as a facilitator. In this context, AR as a PD model, facilitates practical knowledge and fosters reflective teaching strategies much more effectively than other PD models. Language teachers should take AR into consideration not only for continuous $\mathrm{PD}$, but also in the interest of students, since taking a self-reflective, critical and systematic approach to exploring their own teaching contexts (Burns 2010). Thus, by means of AR, we will have an opportunity to develop broader understanding and improve better aspects of teaching practices and learning process. Further research can be carried out with multi-cases including more participants from different contexts to examine the long-term impacts of AR on teachers' PD practices.

\section{Acknowledgements}

We would like to share our gratitude to each of the participants that shared their ideas during the course of this research and data collection process.

\section{References}

Atay, D. (2006). Teachers' professional development: Partnerships in research. TESLEJ, 10(2), $1-15$.

Atay, D. (2008). Teacher research for professional development. ELT Journal, 62, 139- 47.

Borg, S. (2003). Teacher cognition in language teaching: A review of research on what language teachers think, know, believe, and do. Language Teaching, 36(2), 81-109.

Borg, S. (2015). Overview - beyond the workshop: CPD for English language teachers. In S. Borg (Ed.), Professional development for English language teachers: Perspectives from higher education in Turkey (pp. 5-12). Ankara: British Council.

Bracey, G. W. (2009). "Some Thoughts as 'Research' Turns 25.” Phi Delta Kappan 90(7), 530531.

Burns, A. (2005). Action research: An evolving paradigm? Language Teaching, 38, 57-74.

Burns, A. (2009). Action research in second language teacher education. In A. Burns \&s J. Richards (Eds.), Cambridge guide to second language teacher education (pp. 289-297). New York: Cambridge University Press.

Burns, A. (2010). Doing action research for English language teachers. A guide for practitioners. New York: Routledge.

Charmaz, K. (2000). Grounded theory: Objectivist and constructivist methods. In N. K. Denzin \& Y. S. Lincoln (Eds.), Handbook of qualitative research (pp. 509-536). Thousand Oaks, CA: Sage. 
Choi, T., \& Andon, N. (2014). Can a teacher certification scheme change ELT classroom practice? ELT Journal, 68(1), 12-21.

Creswell, J. W. (2012). Grounded theory designs. In J. W. Creswell (Ed.), Educational research: Planning, conducting, and evaluating quantitative and qualitative research (pp. 422-500). Boston: Pearson Education.

Cullen, R. (1997). Transfer of training assessing the impact of INSET in Tanzania. In D. Hayes (Ed.), Inservice teacher development: International perspectives. London: Prentice Hall.

Darling-Hammond, L. (1990). Instructional policy into practice: the power of the bottom over the top. Education Evaluation and Policy Analysis, 12(3), 233-241.

Darling-Hammond, L. (2006). Constructing 21st-century teacher education. Journal of Teacher Education, 57, 300-314.

Dikilitaş, K. (2015). Teacher researchers in action. In K. Dikilitaş, R. Smith, \& W. Trotman, (Eds.), Professional development through teacher research, (pp. 47-55). UK: IATEFL.

Feiman-Nemser, S. (2001). From preparation to practice: Designing a continuum to strengthen and sustain teaching. Teachers' College Record, 103(6), 1013-1055.

Freeman, D. (1998). Doing teacher research: From inquiry to understanding. Boston: Heinle and Heinle.

Freeman, D. (2002). The hidden side of the work: Teacher knowledge and learning to teach. Language Teaching, 35(1), 1-13.

Fullan, M. G., \& Miles, M. B. (1992). Getting reform right: what works and what doesn't. Phi Delta Kappan, 73(10), 745-752.

Guskey, T. R., (2000). Evaluating professional development. Thousand Oaks, CA: Corwin Press.

Ingvarson, L. (1998). Professional development as the pursuit of professional standards: The standard-based professional development system. Teaching and Teacher Education, 14(1), 127-140.

Janesick, V. (2000). The choreography of qualitative research design. In N. K. Denzin \& Y. S. Lincoln (Eds.), Handbook of qualitative research (pp. 379-399). Thousand Oaks, CA: Sage.

Johnson, K. E. (2006). The sociocultural turn and its challenges for second language teacher education. TESOL Quarterly, 40(1), 235-257.

Johnson, K. E., \& Golombek, P. R. (2002). Teachers' narrative inquiry as professional development. Cambridge: Cambridge University Press.

Kennedy, A. (2005). Models of continuing professional development: a framework for analysis. Journal of in-service education, 31(2), 235-250.

Kennedy, M. (1998). Form and substance in inservice teacher education (Research Monograph No. 13). Madison, WI: University of Wisconsin-Madison, National Institute of Science Education. Retrieved April 19, 2017, from http://tinyurl.com/6qujdf

Korkmazgil, S. (2015). An investigation into Turkish English language teachers' perceived professional development needs, practices and challenges. (Doctoral dissertation). Retrieved from http://etd.lib.metu.edu.tr/upload/12619513/index.pdf.

Kubanyiova, M. (2012). Teacher development in action: Understanding language teachers' conceptual change. Basingstoke: Palgrave Macmillan.

Kvale, S. (1996). Interviews: An introduction to qualitative research interviewing. Thousand Oaks, CA: Sage.

Lieberman, J., \& Wilkins, E. (2006). The professional development pathways model: From policy to practice. Kappa Delta Pi Record, 42(3), 124-128. 
Little, J. W. (1993). Teachers' professional development in a climate of educational reform. Educational Evaluation and Policy Analysis, 15(2), 129-151.

Little, J. W. (1999). Organizing schools for teacher development. In L. Darling-Hammond and G. Sykes (Eds.), Teaching as the learning profession: Handbook of policy and practice (pp. 233-262). San Francisco: Jossey-Bass.

Mann, S. (2010). The language teacher's development. Language Teaching, 38, 103-118.

Miles, M. B., \& Huberman, M. (1994). Qualitative data analysis: An expanded sourcebook. Thousand Oaks, CA: Sage.

Mills, G. (2007). Action research: A guide for the teacher researcher (3rd ed.). Upper Saddle River, NJ: Pearson Education.

Özer, B. (2004). In-service training of teachers in Turkey at the beginning of the 2000s. Journal of In-service Education, 30(1), 89-100.

Richards, J. C. (2008). Second language teacher education today. RELC Journal, 39, 158-177.

Richards, J. C., \& Farrell, T. S. C. (2005). Professional development for language teachers: strategies for teacher learning. New York: Cambridge University Press.

Schön, D. A. (1983). The Reflective practitioner: How professionals think in action. Aldershot: Arena.

Stake, R. E. (2000). Case studies. In N. K. Denzin, \& Y. S. Lincoln (Eds.), Handbook of Qualitative Research (pp. 435-453). Thousand Oaks, CA: Sage.

Turhan, İ. E., \& Arıkan, A. (2009). English language teacher development with and without a teacher trainer: ELT instructors' perceptions. E-journal of New World Sciences Academy, 4(2). Retrieved April 19, 2017, from http://files.eric.ed.gov/fulltext/ED506221.pdf

Uysal, H. H. (2012). Evaluation of an in-service training program for primary-school language teachers in Turkey. Australian Journal of Teacher Education, 37(7), 14-29.

Villegas-Reimers, E. (2003). Teacher professional development: An international review of literature. UNESCO: International Institute for Educational Planning.

Williams, M., \& Burden, R. L. (1997). Psychology for language teachers: A social constructivist approach. Cambridge: Cambridge University Press.

Wyatt, M., \& Dikilitaş, K. (2015). English language teachers becoming more efficacious through research engagement at their Turkish university. Educational Action Research, 24(4), 550-570.

Wyatt, M., \& Oncevska Ager, E. (2016). Teachers' cognitions regarding continuing professional development. ELT Journal, 71 (2): 171-185.

\section{Appendix A. Semi-Structured Interview Questions}

\section{A.1. Perceptions of professional development}

1. Can you define the term "professional development" and clarify what do you understand from it? How do you define it by using a single adjective? Why? What are the aims of professional development for you?

2. What kind of professional development methods or tools you are aware of?

3. What do you think about the role of professional development in your career? Why?

4. How do you feel about the role of professional development in your teaching context?

\section{A.2. Practices of professional development}


1. What types of professional development activities and practices do you engage in on a regular basis? Was the participation in these activities on a volunteer basis?

2. Which professional development methods have you used so far? What do you do as a teacher for your professional development for yourself?

3. What are the factors that facilitate your participation to professional development activities?

4. What kind of challenges that hinder your professional development do you experience? Do you think these problems are mainly intrinsic? or Do they mainly stem from extrinsic factors (your institution, educational policies, working conditions, colleagues, curriculum, etc.)?

\section{A.3. Professional development characteristics that facilitate developing practical knowledge}

1. Can you list professional development activities from the most effective to the least for developing practical knowledge? How effective do you find these activities to be in enhancing your teaching ability? In which aspects did you benefit from these activities?

2. How have you been able to implement what you have learned from the professional development activities in which you have participated recently? How can you make use of them? Do you think the professional development activities manage their aims in your teaching context? If yes, how? If not, why?

3. Do you consider yourself as reflective in your teaching professional development? Can you please support your answer with examples or instances from your teaching?

4. Are there any changes you would request related to professional development activities? Do you have any recommendations to make them more effective for developing practical knowledge?

\section{Copyrights}

Copyright for this article is retained by the author(s), with first publication rights granted to the Journal.

This is an open-access article distributed under the terms and conditions of the Creative Commons Attribution license (CC BY-NC-ND) (http://creativecommons.org/licenses/by-nc-nd/4.0/). 